University of Wollongong

Research Online

Faculty of Social Sciences - Papers (Archive) Faculty of Arts, Social Sciences \& Humanities

2014

Australian mothers' notions of risk and uncertainty in relation to their preteen children

Jan Wright

University of Wollongong, jwright@uow.edu.au

Christine Halse

Deakin University

Gary Levy

Deakin University

Catherine Hartung

Deakin University, cjh966@uow.edu.au

Follow this and additional works at: https://ro.uow.edu.au/sspapers

Part of the Education Commons, and the Social and Behavioral Sciences Commons

Research Online is the open access institutional repository for the University of Wollongong. For further information contact the UOW Library: research-pubs@uow.edu.au 


\title{
Australian mothers' notions of risk and uncertainty in relation to their pre-teen children
}

\begin{abstract}
In this article we examine the ways discourses of risk manifested and played out within and across two groups of Australian mothers living in two large urban centres in Australia: the first comprised of mothers who had a pre-teen child diagnosed with an eating disorder $(n=13)$; the second of mothers who had a preteen child without the symptoms or diagnosis of an eating disorder $(n=13)$. In 2011 and 2012, we conducted in-depth interviews with the mothers in their homes on their ideas about health and their relationships with their children. An analysis of the data collected from these interviews indicated that having a pre-teen child diagnosed with an eating disorder had a decisive impact on how the mothers constituted and responded to risk. For mothers, who had a pre-teen child with an eating disorder, risk was intensified by bio-medical discourses. The particular intensifications of risk limited the ways in which mothers could act and often threatened to undermine their abilities as competent carers. By contrast, the mothers who did not have a pre-teen child with an eating disorder spoke about risk less directly, and with less sense of immediacy. Where these mothers acknowledged risk discourses particularly in regard to health, they were in a stronger position to negotiate them. Our analysis indicates that the ways in which mothers responded to risk is contingent on circumstances and contexts. Mothers' responses to risk were related to the calculability of the risk and their perceived capacity to manage it.
\end{abstract}

\section{Keywords}

uncertainty, risk, notions, teen, mothers, children, australian, pre, their, relation

\section{Disciplines}

Education | Social and Behavioral Sciences

\section{Publication Details}

Wright, J., Halse, C., Levy, G. \& Hartung, C. (2014). Australian mothers' notions of risk and uncertainty in relation to their pre-teen children. Health Risk \& Society, 16 (2), 185-198. 


\section{Holding risk to account: Australian mothers' notions of risk and uncertainty in relation to their preteen children}

\section{Introduction}

A growing body of literature examining the relationship between parenting and risk points to mothers as being particularly susceptible to dominant notions of risk (see for example Lee, Macvarish and Bristow 2010). This perceived susceptibility is primarily explained in terms of mothers being held responsible for not only their own bodies and wellbeing but also for their children's 'normal' cognitive, social and emotional development. As a result, mothers fall under the constant and scrutinising gaze of themselves, health experts, and the public at large. For mothers whose children do not conform to social ideas of 'normality', exposure to expert intervention to manage the effects of risk are likely to be substantial (Oulton and Heyman 2009).

The purpose of this paper is to examine the various ways discourses of risk manifested and played out within and across two groups of Australian mothers: the first comprised of mothers who had a pre-teen child diagnosed with an eating disorder; the second of mothers who had a pre-teen child without the symptoms or diagnosis of an eating disorder. An analysis of the interviews conducted with the two groups pointed to the different ways risk operated between and within the groups, pointing to the importance of context, circumstances and dispositions. In the final section of our paper we draw some conclusions that address aspects of established risk theory while also suggesting some ways in which that theory might be usefully informed by the findings from our study. 


\section{Risk in social and cultural theory}

The notion of risk and its influence in/on contemporary neo-liberal societies and subjectivities has been a major area of interest among social and cultural theorists in the past three decades, much of it growing out Beck’s (1992) theorization of risk as a defining feature of contemporary society (see for example, the edited collections and monographs by Adam, et al. 2000, Denney 2005, Lupton 1999, 2013). Since the mid-1980s Beck has argued that the processes of modernisation have generated new distributions of risk alongside new distributions of wealth, the consequences of which are a set a 'global dangers' (Beck 2007, p. 21) related to the environment, geo-political security, safe energy production, new technologies and so on. Beck’s ‘big picture’ view contends that post-industrial societies are increasingly underpinned and organised by a set of manufactured risks shaping social and even interpersonal relations through their real or latent effects. In this context individuals are positioned as responsible for managing these risks in accordance with neo-liberal ideals. These risks manifest as various kinds and intensities of risk consciousness in and through the everyday lives of people. A ubiquitous area of risk is that related to health and specifically, according to Lupton (1999), in relation to contemporary representations of food and eating.

Amongst those working with theoretical notions of risk, there is an argument that Beck's version of risk is too 'homogenous and all embracing' (Rose 2002, p. 213). Far from being homogenous, Rose (2002, p. 214) argues that risk in these times is made up of a 'motley array of ways of thinking and acting' without a common cause. As an alternative, Dean (1999, p. 136) proposes a shift away from totalising narratives towards empirically-based analyses, whereby specific types of risk rationalities and practices are viewed as heterogeneous. Dean (1999, p. 142) argues that identifying different types of risk is valuable because 'by identifying its different forms, we might begin to understand the diversity of understandings of risk, how risk can be linked to quite different programmes and 
technologies, and the way the vocabulary of risk can cross and bind together quite distinct sets of practices'.

The empirical program of examining risks in their different forms and constitution has been taken up by those conducting research in the sociology of health. Although there is some argument that the field should look for other frames of reference beyond 'risk', Lee and her colleagues (Lee et al. 2010) argue, in their editorial to a special issue of Health, Risk and Society, that where parent-child relationships are concerned, empirical work suggests that ‘society emerges as clearly "risk-centred”' (p. 298) and that 'risk consciousness emerges as a very powerful influence over parental experience' (p. 298). In her paper in this special issue, Knaak (2010) argues for the importance of developing theoretical understandings of risk in relation to contemporary parenting culture by exploring 'the meaning of risk in different mothering contexts, and [examining] how mothers come to conceptualise what 'counts' as a risk or benefit for their children in different mothering situations' (Knaak 2010, p. 346)

The papers in the special issue, like much of the work in this area of risk and parenting are primarily focused on infants and young children: specifically on pregnancy, infant and child feeding and constructions of risk in relation to child safety. Our paper builds on this work and other work on parents’ assessment and management of risk (e.g. Backett-Milburn et al. 2006), but focuses on a group as yet missing from the literature, to examine what risk consciousness looks like for mothers whose pre-teen children are facing a life threatening illness, the risks of which are assumed to be able to be mitigated by changing parent and child practices. We do this by drawing on interviews conducted with mothers of pre-teen boys and girls diagnosed with an eating disorder. We also use interviews with mothers of children without a diagnosis or symptoms of an eating disorder by way of illustrating how the diagnosis of an eating disorder mobilised a different set of specific and immediate risks. 
These were risks assessed by experts on the basis of clinical authority; they were also risks mothers were held responsible for managing on a daily basis.

\section{Defining eating disorders}

Despite intensified social and government anxiety about the overweight and obesity among children in many affluent societies, eating disorders have emerged as a critical physical and mental health problem among young children (7-13 years) (Madden et al, 2009). An eating disorder is the general label used in the Diagnostic and Statistical Manual of Mental Disorders (DSM-5) for a range of psychiatric conditions involving eating, specifically: anorexia nervosa (restrictive and binge-eating subtypes), bulimia nervosa, Eating Disorder Not Otherwise Specified (EDNOS) and binge eating disorder (BED). In Australia, the incidence of eating disorders among pre-teens is nearly double that of comparable societies such as Canada and the United Kingdom, with a 30 per cent higher boy/girl ratio (Madden et al. 2009).

Traditionally considered a problem of teenage girls and young adult women, the incidence of eating disorders among young children has been attributed to a deeper, more widespread social problem of body dissatisfaction and extreme dieting. Survey data, for example, indicate that the majority of pre-teen children are unhappy with their bodies, anxious about their weight and want to be thinner (Davison et al. 2003, Allen et al. 2008), and 40 per cent regularly use rigid dieting and unhealthy weight loss methods such as purging, including those as young as 5 and 6 years of age (Rolland et al. 1997).

Among pre-teens, eating disorders have both physical and psychological manifestations that can include extreme dieting or food restriction, excessive exercising and body dysmorphia. An eating disorder is often accompanied by other problems such as poor body image, low self-esteem, extreme mood swings, obsessive compulsive behaviours, and/or high levels of 
anxiety and distress. The varied combinations of these factors make eating disorders difficult to diagnose, manage and treat, but children are generally considered to have a better chance of recovery than adult sufferers (Hay 2009). However, eating disorders among pre-teen children are a recent phenomenon and there is limited research data on recovery rates or their longer-term effects. As a result, parents have to rely on the existing knowledge about eating disorders in adolescents and adults and this is troubling. This knowledge points to an average duration of the illness of 5-7 years, high potential for permanent organ damage and long-term psychiatric problems, and the highest mortality rate (up to 20\%) of any psychiatric problem (Madden et al. 2009).

Recent research points to the particular complexities of 'eating disorders' amongst young children. While these children may indeed be unhappy about their appearance and anxious about their weight, our research (Author 2, et al. 2007; Author 1 and 2, 2013) and that of others (Madden et al. 2009) suggest that eating disorders amongst younger children and particularly pre-teen boys is more complex and cannot be easily attributed to body dissatisfaction. Rather, disordered eating seems to be an expression of other issues such as high levels of anxiety. This presents parents of pre-teen children with further challenges since the diagnosis of an 'eating disorder' is not always helpful in anticipating and managing daily behaviours that they see as putting their child's health and indeed life at risk.

\section{The study}

This paper draws on empirical qualitative data collected as part of an Australian Research Council funded study which sought to examine eating disorders among pre-teen children from a socio-cultural perspective, by asking how preteen children and their parents interpret discourses associated with body, health and well-being in the context of contemporary social conditions. The study included a series of semi-structured interviews conducted in 2012 with 
26 Australian mothers of children between the ages of 5 and 13, across a range of demographics but with most families classified as 'middle-class,' based on their level of education and Socio-Economic Index For Area (SEIFA) ranking (Australian Bureau of Statistics, 2011). Thirteen of the twenty-six mothers interviewed had a young child diagnosed with an eating disorder or eating problem. We recruited these families through two large public hospitals with specialist eating disorder units in two Australian capital cities. All of the diagnosed children experienced hospital-based interventions including family therapy, regular weigh-ins and medication. The other half of the mothers in our study did not have children with diagnosed eating problems. These families were recruited by a variety of means, including advertisements in newsletters, magazines and snowballing. Families were selected based on their having at least one child between the ages of 5 and 13. Research ethics approval was gained through the two hospitals involved and Deakin University. Interviews were conducted for the most part in homes, with one researcher interviewing the mother and the other the child. Interviews generally lasted for one hour and were structured as far as possible as conversations. Field notes completed after each interview, documented reflections on the interviews by the interviewers, including emotional and analytical responses to the interviews by both the mothers and the researchers and reflections on the strengths and limitations of the interviews. Both groups of the mothers were asked questions about their meanings of health, family relations, their hopes and aspirations for their children and their children's daily activities. The mothers with children diagnosed with an eating disorder were asked additional questions about how their lives and their child's lives had changed since diagnosis. Interviews were transcribed professionally and pseudonyms were used at this point to preserve anonymity.

Interview transcripts were analysed by research associates using thematic and theoretical coding using QSR NVivo 10. The coding was discussed and refined by the research team. 
One of the recurrent themes that emerged from the analysis was the way in which the mothers talked about managing the risks that might beset their children in the present and future. This prompted a comparison using a matrix analysis (Nvivo Help 2013) between the ways in which the two groups of mothers configured risk in their talk about their children. Comparison with other literature suggested that while the 'risk consciousness' of the mothers with pre-teen children not diagnosed with eating disorders drew on discourses and sources of risk identified in other literature such as that cited above, for the mothers with children diagnosed with an eating disorder risk was configured in very different ways.

\section{Findings}

\section{Risk and mothers with children without an eating disorder}

For the mothers with children without an eating disorder, their talk about risk paralleled studies of similarly placed mothers in the literature (Backett-Milburn et al. 2006, McDermott 2007) and in popular and policy representations of contemporary risks for young people (Kelly 1999, 2003, Evans et al. 2004, Backett-Milburn et al. 2006, McDermott 2007). The mothers' assessment of risks reflected their child's age and gender. The mothers of younger children were more likely to talk about food and friendships, while the mothers of older children were more likely to talk about technology, alcohol and for one mother of a female child, 'boys', as their pre-teen children began to explore a world beyond the home (both virtually and materially). For these mothers, these were risks for which they saw themselves as responsible for protecting their children but, at this stage, within their capacity as a caring parent. The risks were not expressed as a particular source of anxiety or as impinging on the quality of their relationships with their children, nor on the family as a whole. They had developed various 'risk rationalities' (Fullager 2009, p. 124) around which they organised their parenting policies and practices. 
The first area of risk apparent in the mothers' talk was around their children's access to and use of technology. Most of the parents talked about how they monitored and/or limited their children access to and use of technology, including television, DVDs and the internet. For example, Elaine did all she could to limit and police her child's (Emily, aged 12) exposure to computer games which from her perspective were a problem because they were all about 'killing, killing, killing, killing, killing and blood all of the time'. The same surveillance and regulation extended to the use of Facebook, despite protestations from her daughter. For Gaby, Facebook was also designated 'out of bounds' for her children (Greg, aged 10 and Georgia, aged 12) until they 'reach 18 and they move out of home'. As long as she had control over their behaviour, 'they're pretty much never going to get it. I think it's just, it's asking for trouble'. Like the other mothers in the study who limited their children's access to the internet, her decision was explained with reference to popular and institutional discourses associating risk with computer games and social media, and her responsibility as a mother to control this. For Gaby, the underlying problem was that her children were, 'young and susceptible, it's just fuel for anxiety'. Ianthe also assessed and acted on the potential risks she perceived as associated with M-rated movies and violent computer games for her children (Ishmael, aged 7 and Ivan, aged 10). These risks were, however, explained in terms of their effects on brain development, 'it's to do with brain development, it's nothing to do with me being a horrible mother, it's how I feel, you know. And so I'm very strict about like those sorts of things they watch.' In this case, the authority of neuropsychology provided Ianthe with the means to justify her assessment and actions in relation to restricting her children's interactions with media.

The second area of risk evident from the mothers' interviews was the relationship between food and health. For example, Hannah talked about feeding her children healthy food in part at least to prevent them becoming 'fat', and Gabby restricted her children's intake of soft 
drinks and gum to protect her children's gums and teeth. For some this was an area of some mild anxiety but most of the non-ED mothers were sanguine about the extent of the risk and their capacity to manage it. Like the parents in the study by Backett-Milburn and her colleagues (Backett-Milburn et al. 2006), they did not want a preoccupation with food to interfere with other aspects of family life or personal pleasures. Ianthe's comments below sum this up:

we're worried about food and what we eat, and you know, because we're not thin people, you know, we've got weight on, so it's a constant, you've got to constantly be on top of it and thinking you've got to exercise, but you don't want it to take over your whole life and happiness because food, to our family, also is such a happy time to be together, to commune, to talk over things and food is always a part of it. (Ianthe)

These mothers of pre-teen children still had considerable control over the food their children ate. However, Francesca's response to proposed changes at her children's canteen points to the importance limiting 'unhealthy food' had for most of the mothers. 'There was not one item there that I could really suggest or that I would allow my children to have'. She planned a meeting with the headmaster 'because I think I can't really let this sit'. She anticipated the battles with her children (Felix, aged 8 and Frank, aged 11) that would ensue if she denied them the opportunity to use the canteen, however given her perceived risks to their health, this would have to be the case: 'What's on the menu? There are trans fat bombs. Do I want to kill my children? No.' Francesca is a good example of Fullager's (2009, p. 122) description of the way risk discourses 'work to mobilize emotion or affect as they attempt to shape how we conduct ourselves as active, responsible, healthy subjects'. Healthy eating discourses around the dangers of 'trans fats', sugar and processed food - the kind of food to be sold at the canteen - for Francesca, mobilised considerable anxiety, frustration and anger. On the other hand, when she is in control, she is happy to provide a treat for her children of hot 
chocolate for breakfast, or a mini chocolate bar together with the fruit and vegetables she supplies for lunch. These examples highlight the way in which the mothers operated simultaneously with both a generalised level of risk consciousness (monitoring what is prepared and eaten within the family), while at the same time responding to very specific 'truths' circulating within public health discourses (good/bad foods, healthy/unhealthy eating, safe/dangerous).

The third area that received attention from the mothers was their responsibility to protect their child against present risks and to assist them in becoming autonomous individuals who could successfully deal with future risks on their own. Natalie, for example, saw her primary role as a mother to be about teaching her daughter (Nyssa, aged 9) how to protect herself, 'especially now with the boy craze starting'. Until Nyssa was able to do so herself, Natalie needed 'to protect her and make sure she gets everything she needs'. These twin tasks of protection and provision (Maher et al. 2010) defined and delimited Natalie's role and identity as mother. Preparing her for a future (in which there would be boys and presumably men) was about helping her to learn to 'respect herself and know her self-worth' so she would be better equipped to protect herself against 'being treated badly when she gets older'.

For Kelly preparation for future risks involved surviving present ones and so she was relatively sanguine about her more unruly daughter, Kayla (aged 9), taking risks that placed her in contention with the authority of the school.

I'm quite confident about letting Krys [aged 12] have a lot of freedoms because she’s so damn worried about things going wrong, but I know she won't; whereas Kayla I already predict she'll be wagging school. It's just she hasn't worked out how to do it yet. She'll get there, but then I did, so I think that's also about honesty. I know I was a terror to my mother, so I expect it. 
Kelly suggests here that, from her own experience, opening one’s self to the dangers and uncertainties accompanying risk-taking behaviours can have its pleasures and rewards (Lupton and Tulloch 2002) and that these daring deeds are survivable, for both child and mother. In a similar way Hannah assessed the risks likely to beset her two very different children and set about implementing gender-challenging strategies to cultivate more 'roughness and toughness' in one son (Harry, aged 6) who was 'lovely and sensitive and soft', while encouraging her daughter (Holly, aged 8) to adopt the same qualities ('roughness and toughness'). Kelly and Hannah are both examples of mothers recognising the generative, as opposed to the limiting, capacities of risk, or as Giddens (1999, p. 10) suggests, understanding risk as having the potential to be ‘a positive or energising phenomenon'.

The above examples illustrate how risk is contingent, contextual and changeable, according to time and circumstances (Duff 2003, Lidskog and Sundqvist 2012). For some of the mothers, risk was assumed to have a positive valency, intrinsic to life, and therefore unavoidable to some extent. For others, the risks that worried them were those that might erode their capacity to control and manage their child, including the giving of freedoms if the mother thought the child might not use these in ways the mother thought appropriate and safe. For the non-ED mothers, the risks they perceived their children facing in the present were calculable, measurable and manageable. Their consciousness of risks was not 'unusual' and are shared with other mothers of pre-teen children; indeed, part of the social discourse of growing up in the contemporary world. This allowed them the space to contemplate the options and choices available for themselves and their children.

\section{Risk and mothers with children with an eating disorder}

By contrast with the 'normative and shared' experience of the mothers with children not diagnosed with eating disorders, from the time of diagnosis and decisive intervention by the 
biomedical system, the ED mothers found themselves consumed by competing and contradictory demands and intensified activity that threatened to undermine and/or reorder their foundations as competent, capable and caring. One of the most striking features within the cohort of ED mothers was the way in which risk consciousness became more acute with the onset of the illness and consequent intervention. For example, in the following quotes, it is evident how the language used by these mothers reflects an intensification of fear around the safety and wellbeing of their child.

It was only on that very day that I looked at her and I knew there was something wrong ... that's when I realised she was severely underweight and her anxiety was just peaking [and] everything came crashing down. (Felicity, daughter Freya aged 11)

I was just stricken with grief because I didn't know what was happening to her and she was fading and fading, and I didn’t know how to get help. (Heather, daughter Hayley aged 12)

In my desperation, I just started ringing around by myself ... At that stage, I was ringing anybody and everybody who I could find, trying to get some help. (Annabel, daughter April aged 12)

You know you feel like you've been ripped off your foundations ... my world was falling down, really ... sensational danger looming. (Mariela, daughter Maddy aged 10)

For these mothers, the shock and severity of being confronted with their child's eating disorder escalated the risks facing their child to catastrophic proportions. Unlike the non-ED mothers, their capacity to protect their children against risks was seriously undermined by 
their profound uncertainty in calculating the risk, and in their capacity to protect their children now, let alone in the future.

The dangerous contingencies of risk had very different effects under the acute conditions experienced by the ED mothers. When the conditions of the illness first presented acute dangers to their child's well-being and lives, they generated an intensity of concern in the mothers that necessitated external support and intervention. Not surprisingly, when confronted with a life-threatening illness to their child, the ED mothers' sense of risk to their child became, in the crisis, immeasurable. Theoretically, it could be argued here that risk reaches its limits, becoming intolerable when it assumes the face of uncertainty. Evans (2013, p. 28) suggests, 'if there is a singularity to fear it is uncertainty ... brought about by a sense that the course of events is beyond the subject's control' (italics in original).

The intensification of risk becomes evident when observing the ways in which the ED mothers sought expert assistance when they recognised the limits of their own capacities to adequately deal with the crisis. Unable to provide the necessary safety net, the mothers were forced by the severity of the illness to draw on medical and allied health professionals for support and guidance, thus committing themselves and their children to medicalized discourses and practices, which diminished her authority to 'know' her child and her illness. For example, Heather's assessment of her child's illness was redefined once she sought expert health, mother of Haley (aged 12) recalled,

That's all I kept saying, 'She’s still eating. How can you tell me it's anorexia if she’s still eating; I don’t get it, something's missing'. And she said to me, 'It is - she’s off the charts [in terms of weight]. I can’t even explain where your daughter sits because she’s down here, she’s off the chart. She needs help straight away’. 
With this initial diagnosis, Heather had to hand over control of her child's daily life to experts. Hayley’s extreme weight loss was so acute, her life was at risk and it seemed that medical intervention and hospitalisation was the only way of saving her. For the ED mothers, decisions about the care of their children were taken out of their hands; the risks were calculated by medical professionals and presented as life-threatening. For example, for Annabel, the medical 'resources were really tough',

I mean as soon as we got here and saw [the doctor], he said, 'Well if you don't put her on medication, you're going to go nowhere fast'. He said, 'You've got to medicate her, or you've got no hope'. And he said, 'It's going to be 6 months of hell'.

With this kind of radical intervention (e.g. closely monitored or forced eating; frequent testing and measuring of weight, blood pressure, and other vital signs; medication in some instances; constant surveillance), a dramatic shift took place in how the burden of risk was addressed. ED mothers had their risk consciousness sharpened to a point where options and alternatives became curtailed. In these moments, the ED mothers lost their capacity to make decisions in relation to the nature of risk, or to have much influence over the control and direction of decisions. The risks associated with the management and treatment of the child/disorder tended towards the singular and uniform, determined primarily by biomedical imperatives. Bronwyn (son Benjamin aged 10) enunciated the (apparent) stakes unequivocally: 'Yeah well my biggest fear is, if you don’t eat you die, like'. Such conditions shook the foundations of their maternal identities and confidence,

I thought I was a good parent, with good boundaries, you know. Whereas now you have no confidence whatsoever, as far as making decisions for the girls... so you become a lot less sure of yourself. After we've been through what we've been through... (Annabel). 
Their confidence in themselves as mothers was further shaken by their perceived incapacity to impact on their child’s 'at risk' behaviour, without the support (threat) of medical intervention. For example, Bronwyn's frustration and anxiety is evident in her observation: 'Yeah and like, and he doesn’t listen, like he does, he understands about death but he, to him there's nothing wrong with him'. For Ilona too, regular threats from her son (Irwin, aged 9) to kill himself set her up for 'the biggest battle of my life'. For the ED mothers, at least at this point in the diagnosis, managing their child's risk was all consuming; there seemed to be no limit to the risk and the need to monitor their children's behaviour for the foreseeable future. As Heather succinctly expressed it, 'So, I was just thinking, my God, either she’s going to die, or this is going to be with us for the rest of our lives and this is, oh my gosh, oh my God, like wow'. Similarly, for Felicity, her fear was the risk of her daughter Freya’s life threatening illness becoming entrenched or permanent, 'It's my one fear that for the rest of her life...is this going to haunt her, is it always going to be there, is it always going to be an issue for her? I fear it, and I’m not asking, it's my fear'.

Although the mothers had to temporarily relinquish primary control to the medical team, they were expected to take responsibility for the close monitoring of their child between visits to the clinic. They commonly had to engage in a variety of practices to micro-manage the calculated needs of their sick child as determined by the clinicians, where the primary goal was weight gain, and avoiding further weight loss. These practices included structuring the diet, meals and meal times; the surveillance of exercise; administration of medicines; attending family therapy, etc. Such practices captured all members of the family, not just the mothers. The reach and effect of the medical expertise persisted beyond the hospital/clinic. The imperative of weight gain, and the threat of hospitalisation, or further deprivation of 
activities that attended failure, further diminished the mothers' freedom to decide on what risks should be attended to or not. Eileen's recount vividly captures some key aspects of this situation,

Like I'm just always at doctors all time, and it's draining, it's really draining, I get really tired, yeah. Trying to fit in work. Like if I wasn’t working for my parents, I wouldn't have been able to work at all, I would have had to stop. Particularly when she first was diagnosed with anorexia, like having to watch everything she ate and make sure that she ate a wide variety of foods and you know, make sure that she put on that weight, that was really hard. (Eileen, daughter E aged 13)

The intensification of risk generated by the eating disorder meant that Eileen had to reorganise much of her life around the management of her child's illness. Other mothers reported similar levels of disruption and reorganisation of their lives. Such micro-surveillance took its toll. Heather, for example, talked somewhat guiltily about the pleasure she took in having some time free from the constant presence of her daughter in her life,

And it was such a nice time not having them here [when her children slept over at a relative's home], because - that sounds terrible, I know, but I have been, literally beside Hayley for every breath that she’s taken for the last, you know...

There were also new risks to the family stability that followed from the attention that the child with the eating disorder now required. This meant that the mothers also had to manage other family relationships so that these did not become disordered as well. Again from Heather, 'But you have to be careful as well, the emphasis on Hayley and also, giving the other two attention as well, you can't reward one. They do know what's happening but it's still hard.’ 
Although having a child with an eating disorder was always deeply distressing for the mothers in our study, diagnosis and particularly 'knowing' how to think and act in relation to the problem rendered the risks more knowable and manageable, and for some led them to reconsider their relationships with their children. For example, Gayle commented on how the experience taught her to, 'have more sort of patience and sort of more understanding of what's been going on with her [daughter]', and for Heather it meant taking life more slowly and spending weekends with her children, rather than catching up on chores after a hard week at work. After the acute stages of diagnosis and hospitalisation, Heather was now also much more sanguine about her child's future. Her interview suggests that she had a greater sense of control over the risks confronting her daughter, and while these still required close monitoring, there was more talk of rewards rather than fears, and a more positive assessment of the future than for some of the other mothers.

And I know that she's going to be okay; it's like I have this vision. I know, I can see what you're going to do; I know exactly how it's going to turn out, but I can't tell her that because she just doesn't hear me (Heather).

What this excerpt points to is the variety of ways in which the ED mothers responded to the intensification of risks to their child. It should be allowed that although each child was diagnosed with, and being treated primarily for an eating disorder, the children and the mothers had to manage different comorbidities, and were at different stages of the illness. Mothers and families also had access to, and brought different resources to their management of risk, in terms of clinical support, family environments, and their own dispositions. Ironically, the areas of risk mentioned by the non-ED mothers were virtually absent in the conversations with the mothers diagnosed with children with eating disorders. Indeed, the kinds of foods that mothers were now expected to feed their children were almost totally 
counter to those judged as 'healthy foods' by the non-ED mothers. Energy dense food such as pizzas, cake, biscuits, fried chicken, chips were all on the menu, while salads and fruit were limited for the children who had to make a target weight by their next visit. One of the concerns for some of the ED mothers was with how this put other family members at risk, when this food became the mainstay of family eating rather than the exception.

A further comment should be made about the mothers of the pre-teen boys diagnosed with eating disorders. For most of these boys, disordered patterns of eating began very early in life, in their first or second year in some cases, and were associated with high levels of anxiety, 'anger issues', or possibly 'autism'. In these cases the mothers had been seeking some kind of explanation from experts for their child's behaviour over a period of years. These children were also more likely to be on a range of drug treatments. Eating was not simply about enough high energy food but about finding creative ways to manage their children's various phobias about food and eating. For these mothers, managing the complexity of their children's lives was both extremely demanding but because of its duration and the uncertainty or resolution, had to be incorporated creatively into the family's everyday lives. 'Expert' knowledge was viewed with more scepticism and like the parents in Oulton and Heyman's (2009, p. 303) study of parents with a child with a severe learning disability, the mothers tended to take on more 'risk ownership’ as a consequence.

\section{Discussion}

A close analysis of the way in which discourses of risk operated within and across the two groups of mothers of pre-teen children with and without eating disorders suggests that risk is conditional on particular contexts, circumstances, and individual dispositions (Duff 2003, Lidskog and Sundqvist, 2012). As pointed out above, the tendency of some risk theory is to postulate grand narratives on a global societal scale related to key issues such as the 
environment, security, health, and international finance. Evans (2013, p. 35) refers to these realms as constituting, geopolitically, a 'catastrophic risk landscape'. While this landscape forms the broad backdrop to our study, such an homogenising approach is problematic when inquiring into some of the more subtle and varied ways that risk operates in concrete contexts with specific individuals.

The literature on mothering and risks points to the strength of discourses or 'grand narratives' assigning to mothers the responsibility for recognizing and anticipating risks and 'managing these risks through reference to expert health' (Lee 2008, p. 489). While much of this literature is concerned with risk consciousness in relation to pregnancy, infant feeding or early childcare, it is clear from popular media and from the considerable literature on healthrelated issues and young people, that the teenage years are considered to be a time when young people are both a risk to themselves and others, and thus in need of management by families, communities and social institutions (Kelly 1999, 2003, Backett-Milburn and Harden 2004). Analysis of the interviews from our study demonstrates how risk consciousness makes its way into the everyday lives of mothers and how this varied within and between the two groups of mothers in the study. For the mothers of pre-teen children without an eating disorder, the risk discourses that were most salient were those related to food, technology and relationships - these provided them with ways of thinking about their children's lives and their responsibilities as mothers in caring for their children now and preparing them for the future. While there is little research for comparison, we would suggest that these are concerns shared by parents of pre-teen children in similar social contexts.

From other research, parents' assessments of safety, dangers and risk seem to change markedly when they have teenage children (see for example Backett-Milburn and Harden 2004). However as Backett-Milburn and Harden (2004, p. 230) point out, how these risks are 
'negotiated and reconstituted in the mundane relations between children and parents in families’ varies considerably. For the non-ED mothers of the pre-teen children in our study social risks were anticipated but not yet acute; they were not sources, at this stage, of any great degree of anxiety. The context for this group was largely the mother's own evaluation of what was worth worrying about, or acting on, in relation to their child. It could be said that the non-ED mothers were able to utilise their 'capacity to aspire' (Appadurai 2013, p. 295) on behalf of their child, a capacity made much more fragile or elusive for the ED mothers. The non-ED mothers were similarly able to engage more hopefully with an 'ethics of possibility' for their child, as opposed to the 'ethics of probability' (Appadurai 2013, p. 295) that governed the tensions and intensifications of risk for the ED mothers and their responses.

Conceivably, before their child's illness, the mothers of the children with eating disorders thought about and negotiated risks in the lives of their pre-teen children in ways not that different from the non-ED mothers in our study. However, with diagnosis, acute and sustained medically informed interventions dominated the way risk was defined and managed by doctors, health workers, mothers and other support people. For these mothers, the more generalised 'social risks' associated with being a child or almost teenager had little claim on their attention in face of the intensity of the immediate risks to their child's well-being, not only the physical consequences of the illness, but also from managing the child's environment (including school, social outings, family) so that the child's social and emotional well-being was maintained. As Kasperson and Kasperson (2005) argue in theorising 'risk consciousness', for all of these mothers their 'risk consciousness' and associated decisionmaking was associated with heightened emotions. At the same time, in contrast to Kasperson and Kasperson’s (2005) argument, their 'risk consciousness' and decision-making were also informed out of necessity by a calculated rationality derived from clinical assessments of the illness and prescriptions for eating and exercise, the outcome of which was measured at each 
visit to the clinic. In this context, what counts as risk was defined by clinicians on the basis of clinical research and experience. Trust in this medical expertise provided a way of managing the uncertainty associated with the illness. For some of the mothers this was more straightforward; their children responded well to the prescribed regime and a favourable outcome seemed likely. For others, especially the mothers of the pre-teen boys, who displayed a more varied range of comorbidities, their uncertainties were less easily assuaged; their trust in expertise less straightforward. These mothers were left with a heightened sense of risk, but one that they had for the most part to manage themselves as a long term commitment.

\section{Conclusion}

In collecting the data for the study reported in this paper, a risk framework provided a useful means to analyse the different ways the mothers configured their relationships with their children and their capacities as caring parents. Our empirical findings challenge any notion of risk as homogenous and point to the ways in which risk rationalities are contingent on circumstances and contexts. We demonstrate how responses to risk are related to the calculability of the risk and to (in this case) mothers' perceived capacity to manage risk. Where managing the risks affecting their children is taken to be a key responsibility of the 'good mother', for the mothers of children with a serious and life threatening illness, the medicalization of risk with diagnosis and their consequent perceived incapacity to both assess/calculate and manage the risks to their child, undermined their confidence in themselves as a caring parent. They were held (and held themselves) both accountable for and ir-reponsibilised (Author 2 and 1 forthcoming) by the circumstances of diagnosis and treatment. Unlike the parents in Oulton and Heyman's (2009) study, they were less able to 
take control; they did not have the confidence to manage, assess or protect their children without the direction and support of medical expertise. Their assessments of risk were also contingent on the response of their child, and the degree to which they could imagine a future free from illness. Through the comparison of the two groups of mothers, this paper provides further evidence of the influence of risk consciousness on parent experience. It conceptualises what counts as risk in two very differing mothering situations and demonstrates how mothers' perceptions and practices are contingent on circumstances; and how these perceptions and circumstances in turn impact on the way mothers understand themselves and act as 'mothers'.

\section{References}

Adam, B., Beck, U., and Van Loon, J., eds., 2000. The Risk Society and Beyond: Critical Issues for Social Theory, London: Sage.

Allen, K.L., Byrne, S.M., McLean, N.J., and Davis, E.A., 2008. Over concern with weight and shape is not the same as body dissatisfaction: Evidence from a prospective study of preadolescent boys and girls. Body Image, 5 (3), 261-270.

Appadurai, A., 2013. The Future as Cultural Fact. Essays on the Global Condition. London: Verso.

Australian Bureau of Statistics, 2011. Socio-Economic Indexes for Areas (SEIFA). Available from:

http://www.abs.gov.au/websitedbs/censushome.nsf/home/seifa2011?opendocument\&navpos $=260$ [Accessed 20 August 2013].

Backett-Milburn, K., and Harden, J., 2004. How children and their families construct and negotiate risk, danger and safety. Childhood, 11 (4), 429-447.

Backett-Milburn, K., Wills, W., Gregory, S., and Lawton, J., 2006. Making sense of eating, weight and risk in the early teenage years: Views and concerns of parents in poorer socioeconomic circumstances. Social Science \& Medicine, 63 (3), 624-635.

Beck, U., 2007. Risk Society. Towards a New Modernity, translated by Mark Ritter. Los Angeles: Sage.

Davison, K. K., Markey, C., and Birch, L., 2003. A longitudinal examination of patterns in girls' weight concerns and body dissatisfaction from ages 5 to 9 years. International Journal of Eating Disorders, 33 (3), 320-332. 
Dean, M., 1999. Risk, calculable and incalculable, In: D. Lupton, ed. Risk and sociocultural theory: new direction and perspectives. Cambridge: Cambridge University Press, 131-159.

Denney, D., 2005. Risk and Society. London: Sage

Duff, C., 2003. The importance of culture and context: rethinking risk and risk management in young drug using populations. Health, Risk \& Society, 5 (3), 285-299.

Evans, B., 2013. Liberal Terror. Cambridge: Polity.

Evans, J., Rich, E., and Davies, B., 2004. The Emperor's new clothes: Fat, thin and overweight. The social fabrication of risk and ill-health. Journal of Teaching in Physical Education, 23 (4), 372-391.

Fullager, S., 2009. Governing Health Family Discourses of Risk and Responsibility. In: J. Wright and V. Harwood eds. Biopolitics and the 'Obesity Epidemic'. New York: Routledge. 108-126.

Giddens, A., 1999. Risk and Responsibility. The Modern Law Review, 62 (1), 1-10.

Hay, P. J., 2009. Editorial: Eating disorders in younger children: Current issues and unanswered questions. The Medical Journal of Australia, 190 (8), 403-404.

Kasperson, J.X., and Kasperson, R.E., 2005. The social contours of risk. London: Earthscan.

Kelly, P., 1999. Wild and tame zones: Regulating the transitions of youth at risk. Journal of Youth Studies, 2 (2), 193-211.

Kelly, P., 2003. Growing up as risky business? Risks, surveillance and the institutionalized mistrust of youth. Journal of Youth Studies, 6 (2), 165-180.

Knaak, S. J., (2010). Contextualising risk, constructing choice: breastfeeding and good mothering in risk society. Health, Risk \& Society, 12 (4): 345-355.

Lee, E. J., 2008. Living with risk in the age of 'intensive motherhood: maternal identity and infant feeding. Health, Risk and Society, 10 (5): 467-477.

Lee, E. J., Macvarish, J., and Bristow, J., 2010. Editorial: Risk, health and parenting culture. Health, Risk \& Society, 12 (4), 293-300.

Lidskog, R., and Sundqvist, G., 2012. Sociology of Risk. In: S. Roeser, R. Hillerbrand, P. Sandin and M. Peterson, eds. Handbook of Risk Theory. Epistemology, Decision Theory, Ethics and Social Implications of Risk. Dordrecht: Springer, 1002-1027.

Lupton, D., ed., 1999. Risk and sociocultural theory: new direction and perspectives. Cambridge: Cambridge University Press.

Lupton, D., 2013. Risk. $2^{\text {nd }}$ ed. New York: Routledge. 
Lupton, D., and Tulloch, J., 2002. 'Life would be pretty dull without risk': voluntary risktaking and its pleasures. Health, Risk \& Society, 4 (2), 113-124.

Madden, S., Morris, A., Zurynski, Y., Kohn, M., and Elliot, E., 2009. Burden of eating disorders in 5-13-year-old children in Australia. Medical Journal of Australia. 190 (8), 410-4.

Maher, J., Fraser, S., and Lindsay, J., 2010. Between provisioning and consuming?: Children, mothers and 'childhood obesity'. Health Sociology Review, 19 (3), 304-316.

McDermott, L., 2007. A governmental analysis of children 'at risk' in a world of physical activity and obesity epidemics. Sociology of Sport Journal, 24 (3), 302-324.

NVivo Help (accessed October 2013) http://help-nv9-

en.qsrinternational.com/nv9_help.htm\#concepts/about_framework_matrices.htm

Oulton, K., and Heyman, B., 2009. Devoted protection: How parents of children with severe learning disabilities manage risks. Health, Risk \& Society, 11 (4), 303-319.

Rolland, K., Farnhill, D., and Griffiths, R.A., 1997. Body figure perceptions and eating attitudes among Australian schoolchildren aged 8 to 12 years. International Journal of Eating Disorders, 21 (3), 273-278.

Rose, N., 2002. At risk of madness. In: T. Baker and J. Simon, eds. Embracing Risk. The Changing Culture of Insurance and Responsibility, Chicago: University of Chicago Press, 209-237.

Steinhausen, HC., 2009. Outcome of eating disorders. Child Adolesc Psychiatr Clin N Am., 18 (1), 225-42. 
British Journal of Sociology of Education.

DOI:10.1080/01425692.2013.800446 